\title{
Simulation Research of a type of Pressure Vessel under Complex Loading Part 1 Component Load of the Numerical Analysis
}

\author{
Yufu Zhang ${ }^{1,2}$ \\ 1. College of Materials Science and Engineering, \\ Lanzhou University of Technology; \\ 2. Gansu Lanpec Technologies Limited \\ Lanzhou, 730050, China \\ E-mail: zhangyufu@lanpec.com

\section{Junchen $\mathrm{Li}^{1,3}$} \\ 1. College of Materials Science and Engineering, \\ Lanzhou University of Technology; \\ 3. State Key Laboratory of Gansu Advanced \\ Non-ferrous Metal Materials, \\ Lanzhou University of Technology \\ Lanzhou, 730050, China \\ E-mail: lijunchen605@163.com \\ Wenming Song \\ Gansu Lanpec Technologies Limited \\ Lanzhou, 730070, China \\ E-mail: yanggrming@lut.cn
}

\author{
Huixia Guo \\ State Key Laboratory of Gansu Advanced \\ Non-ferrous Metal Materials, \\ Lanzhou University of Technology \\ Lanzhou, 730050, China \\ E-mail: guoxj6906@163.com \\ Guirong Yang, Ying Ma \\ College of Materials Science and Engineering, \\ Lanzhou University of Technology \\ Lanzhou, 730050, China \\ E-mail: yanggrming@lut.cn \\ Jie Sheng, Yuan Hao \\ College of Materials Science and Engineering, \\ Lanzhou University of Technology \\ Lanzhou, 730050, China \\ E-mail: shengj605@163.com
}

\begin{abstract}
Macroscopic mechanical response is one of the key factors in designing pressure vessel. A geometric modeling of pressure vessel was established and the mesh of this modeling then generated by using the finite element simulating methods in software ABAQUS. Loading and boundary conditions of dead weight, hydraulic and uniform internal pressure which often suffered pressure vessel were set and calculated by the finite element method. Stress/strain response of pressure vessel in all kinds of alone loading ways were obtained. The results of finite element simulating were in accordance with those of theoretical calculation which provided useful data for research on mechanical response of pressure vessel under complex loading conditions.
\end{abstract}

Keywords-pressure vessel; finite element; simulation; numerical analysis

\section{INTRODUCTION}

With the rapid development of modern industrial technology, pressure vessel is widely used in the industrial fields. It plays an important role[1] in power, petrochemical, metallurgical, light industry, textile, machinery industries. In addition, pressure vessel increasingly tend to be high temperature, high pressure, low temperature, and large-scale and the general use the welding technology, which increasingly causes the improvement of safety operation requirements of pressure vessel[2]. Pressure vessel accidents often lead to disastrous consequences, therefore a good design idea and the mechanical calculation will be the precondition for the pressure vessel safety. Finding out the causes and the laws of failure quickly and accurately is an effective way to reduce the accidents, and at the same time it has far-reaching significance in effectively avoiding the pressure vessel accidents and improving equipment safety and reliability.

For a long period of time in the past, in the container design, because of the force of the container's each part and the lack of accurate and profound understanding in their container strength, a higher safety coefficient was used to attempt to ensure the safety and reliability of container in the pressure vessel design. The main drawback is that there is no difference in the influence on strength between the membrane stress and other local stress, and think onesidedly no matter the whole stress or local stress, as long as it reaches the yield limit, the whole container will lose the ability to work normally-failure. In fact, when local stress reaches the yield limit, the stress in most other areas of containers is still far lower than this value. Therefore, not only the whole pressure vessel will not achieve the yield degree but the container local stress growth which has reached the yield will be affected by this part of the restrictions, which won't cause pressure container failure. With the development of all kinds of industry, people have more extensive and deep understanding for the pressure 
vessel[3]. Especially the application of the computer simulation technology and the development of the theory of finite element allow people to make an actual analysis on the stress and deformation in each parts of pressure vessel. With a relatively accurate stress solution, combining with the rich experience accumulated in the pressure vessel experiment and use, classifying the stress of pressure vessel and setting the priorities, respectively according to the degree of all kinds stress' influence on the pressure vessel, using different safety coefficient and allowable stress values' limitation can make the most of the material potential into full use and save materials as well as reduce economic loss[4].

This study is based on the above research and theory and tries to use the finite element simulation software ABAQUS calculation pressure vessel under complicated load of macro-local mechanical response. In this process, using submodel related macro and local response, the son technique can be applied to model the complex geometric parts of more accurate stress/strain calculation. This paper is a pressure vessel macro simulation model in the component load of the numerical analysis part. It introduces a pressure vessel from geometric model building, the definition of the material properties and the finite element mesh division in self-respect, hydraulic, internal pressure load respectively under the action of macro mechanics response of numerical calculation. Finally, the finite element simulation resulted from the classical theoretical calculation are compared. The comparison proved the accuracy of the numerical results with the macro simulation model of meshing efficiency.

\section{A PRESSURE VESSEL GEOMETRY MODELING}

Main geometric parameters of pressure vessel are shown in Tab.1, in which geometric parameters aren't on this list because of the large amount. Pressure vessel materials are composed by the 2205 dual phase steel with inner thickness of $4 \mathrm{~mm}$ and the16MnR outer steel with the thickness of $80 \mathrm{~mm}$. In order to get more effective numerical calculation results, the weld on pressure vessel can also be seen as materials with different attributes. The concrete material properties are listed in Tab.2. Tab.3 presents design parameters in pressure vessel.

TABLE I. GEOMETRY PARAMETERS OF PRESSURE VESSEL

\begin{tabular}{|c|c|c|}
\hline Parts & Structure Parameters & Sizes(mm) \\
\hline \multirow{4}{*}{ Barrel } & Inside & 1600 \\
\cline { 2 - 3 } & Barrel length & 8000 \\
\cline { 2 - 3 } & Wall thickness & $80+4$ \\
\hline \multirow{4}{*}{ Head } & $\begin{array}{c}\text { Ellipsoid head long } \\
\text { radius }\end{array}$ & 800 \\
\cline { 2 - 3 } & $\begin{array}{c}\text { Ellipsoid head short } \\
\text { radius }\end{array}$ & 400 \\
\cline { 2 - 3 } & Straight side length & 50 \\
\hline
\end{tabular}

TABLE II. PRESSURE VESSEL DESIGN PARAMETERS

\begin{tabular}{|c|c|c|c|c|}
\hline $\begin{array}{c}\text { Design } \\
\text { pressure } \\
(\mathbf{P}, \mathbf{P a}) \\
\end{array}$ & $\begin{array}{c}\text { Design } \\
\text { temperature } \\
\left(\mathrm{T},{ }^{\circ} \mathrm{C}\right)\end{array}$ & $\begin{array}{c}\text { Barrel } \\
\text { density } \\
\left(\rho, \mathrm{kg} / \mathrm{m}^{3}\right) \\
\end{array}$ & $\begin{array}{c}\text { Barrel } \\
\text { quality } \\
(\mathrm{M}, \mathrm{t}) \\
\end{array}$ & $\begin{array}{c}\text { Container } \\
\text { volume } \\
\left(\mathbf{v}, \mathbf{m}^{3}\right) \\
\end{array}$ \\
\hline $14 \mathrm{e} 6$ & 70 & 7930 & $\begin{array}{c}34.45 \\
\text { (ABAQUS } \\
\text { output) }\end{array}$ & 17.36 \\
\hline TABLE III. & \multicolumn{4}{|c|}{ PRESSURE CONTAINER MATERIAL PARAMETERS LIST } \\
\hline Material & SAF2205 & $\begin{array}{c}\text { SAF2205 } \\
\text { weld }\end{array}$ & $16 \mathrm{MnR}$ & $\begin{array}{c}\text { 16MnR } \\
\text { weld }\end{array}$ \\
\hline $\begin{array}{l}\text { Density } \\
\left(\mathbf{t} / \mathbf{m m}^{3}\right)\end{array}$ & $7.93 e-9$ & $7.93 e-9$ & $7.85 e-9$ & $7.85 e-9$ \\
\hline $\begin{array}{c}\text { Elastic } \\
\text { modulus } \\
(\text { GPa })\end{array}$ & 195.8669 & 213.2719 & 209 & 209 \\
\hline $\begin{array}{l}\text { Poisson's } \\
\text { ratio }\end{array}$ & 0.3 & 0.3 & 0.28 & 0.28 \\
\hline $\begin{array}{c}\text { Yield } \\
\text { strength } \\
(\mathrm{MPa})\end{array}$ & 625 & 716 & 345 & 450 \\
\hline $\begin{array}{c}\text { Tensile } \\
\text { strength } \\
(\mathrm{MPa})\end{array}$ & 824 & 904 & 535 & 545 \\
\hline
\end{tabular}

According to the above geometric parameters and the use of fission merger modeling method, the finite element software ABAQUS was established in pressure vessel macroscopic geometric model, as the geometric model is shown in Fig.1. In addition, the different part of the pressure vessel material, according to the material parameters list, defines corresponding material properties.
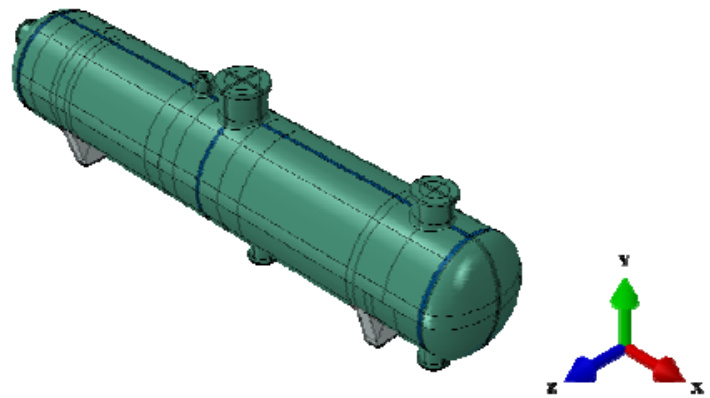

Figure 1. Geometric model of pressure vessel

\section{THE DIVISION OF FINITE ELEMENT MESHES}

Grid partition is a very important content in the finite element calculation. The stand or fall of meshing directly determines whether the calculation results are accurate or not. When parting this pressure vessel by mesh division, the first pressure vessel needs to disseminate seeds in whole. In order to calculate accurately, it requires that all grid use hexahedron units. The reason why grid division way uses structured grid and scanning grid is that the structured grid and scanning for hexahedron mesh unit analysis precision is higher. Before Specific mesh, we need to make use of Medial Axis algorithm to the division of geometric model cutting which is divided into some simple shape, and then use structured grid division mesh technology so that we can get rules of the hexahedral element. Before Specific mesh, 
we need to make use of Medial Axis algorithm to the division of geometric model cutting which is divided into some simple shape, and then use structured grid division mesh technology so that we can get rules of the hexahedral element. After meshing, grid quality can be checked specially for solid, geometric area or unit in ABAQUS. Checking and analysis can lead to unit of mistakes or warning information which will be displayed with high brightness will tell the percentage of the total amount of grid. The effectiveness of the grid can be further judged through checking the grid quality[5]. The finite element mesh model of pressure vessel is shown in Fig.2.

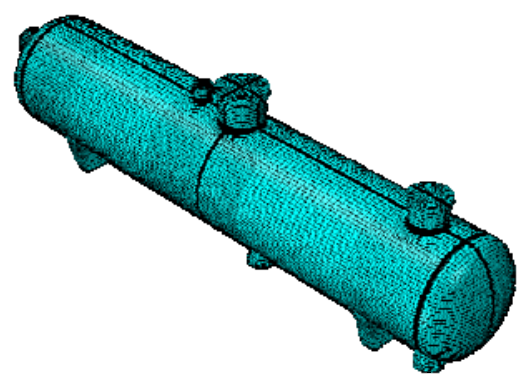

Figure 2. Grid partition of pressure vessel

\section{THE CALCULATION OF PRESSURE VESSEL UNDER THE WEIGHT OF THE MECHANICAL RESPONSE}

The weight of pressure vessel is more than 30 tons, so the mechanical response under the self weight is not allowed to be neglected. The corresponding calculation can be taken by selecting self weight load in the finite element software ABAQUS. In the process of calculation, knowing the volume of each unit, the quality of each unit can be calculated as long as the material density of pressure vessel is known. The density and acceleration of gravity of 9.8 $\mathrm{N} / \mathrm{kg}$ is defined in material parameters so that we can work out the dead weight of each unit. Under such a distributed action of gravity, pressure vessel will present an obvious stress strain response[6]. Fig.3 is a schematic diagram of pressure vessel under weight loading.

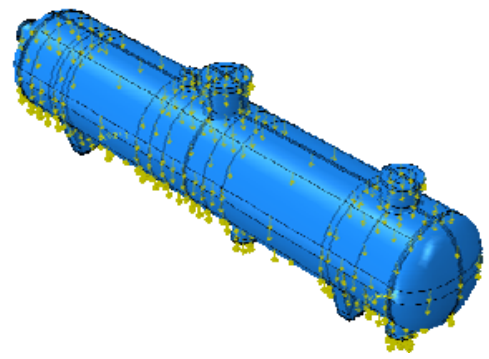

Figure 3. Schematic diagram of pressure vessel under weight loading
The following is the calculation results of finite element. Fig.4(a) is a Mises stress distribution of pressure vessel under weight loading. Fig.4(b) is displacement profile of pressure vessel under weight loading. From these two pictures we can see that the largest position of stress is in the joint of support and pressure vessel, which is tally with the actual situation. There is a phenomenon of big stress concentration on the connection edge. The maximal displacement appeared in the middle part of pressure vessel.

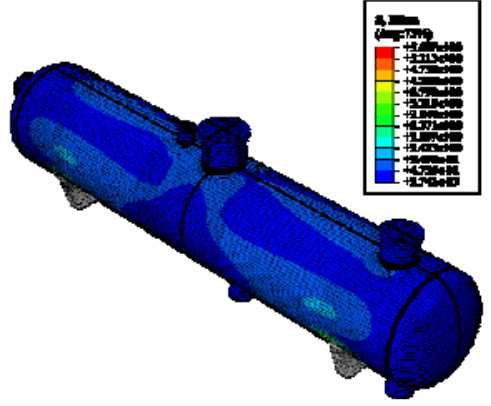

(a) Mises stress distribution

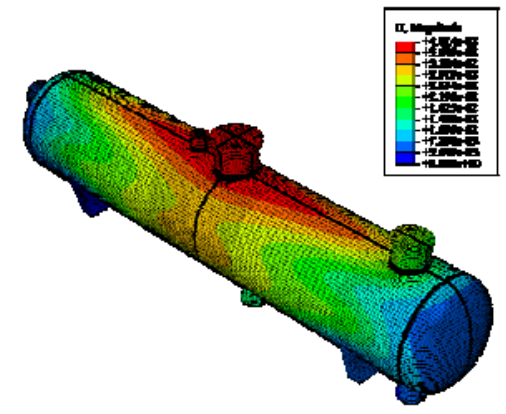

(b) Displacement distribution

Figure 4. Finite element calculation results of pressure vessel under weight loading

Extraction bearing a reaction and theoretical value comparison:

1) According to the theoretical calculation of the pressure vessel weight loading:

$\mathrm{G}=\mathrm{mg}=34.45 \mathrm{t} * 9800 \mathrm{~N} / \mathrm{t}=337610 \mathrm{~N}$

2) ABAQUS about extracting two support a reaction:

The left bearing reaction of supports: $F 1=166616 \mathrm{~N}$

The right bearing reaction of supports: F2 $=169825 \mathrm{~N}$

The sum of left and right bearing reaction of supports:

$\mathrm{F}=\mathrm{F} 1+\mathrm{F} 2=166616 \mathrm{~N}+169825 \mathrm{~N}=336441 \mathrm{~N}$

3) Errors

$(\mathrm{F}-\mathrm{G}) / \mathrm{G} * 100 \%=(337610-336441) / 337610=0.35 \%$

The error of reaction and own gravity for pressure vessel of ABAQUS calculation is within $5 \%$, so we can believe that a geometric model and grid partitioning results established under the weight of pressure vessel is effective. In subsequent finite element calculation of internal pressure and hydraulic load, this grid is also used. 


\section{CALCULATION OF PRESSURE VESSEL UNDER HYDRAULIC LOAD THE MECHANICAL RESPONSE}

The mechanical response under the action of hydraulic should be simplified. The influence of flowing liquid on pressure vessel can be ignored in calculation, while the influence of the gravity of static liquid on pressure vessel is only considered[7]. Firstly, pressure of liquid on the inner wall of pressure vessel is calculated, and then the calculated pressure is loaded as load loading to the inner surface of vessel pressure, finally the function expression of liquid' pressure is set in the ABAQUS. Liquid in the container is water in calculation with density of $1000 \mathrm{~kg} / \mathrm{m}^{3}$ and acceleration of gravity is $9.8 \mathrm{~N} / \mathrm{kg}$. The function expression of liquid' pressure is $P=\rho g h$. Fig.5 is the schematic diagram of pressure vessel under hydraulic load.

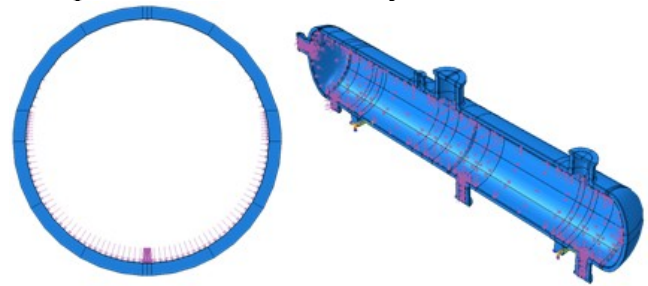

Figure 5. Schematic diagram of pressure vessel under hydraulic loading

The following is the calculation results of finite element. Fig.6(a) is Mises stress distribution of pressure vessel under hydraulic load. Fig.6(b) is displacement profile of pressure vessel under hydraulic load. According to the calculation, the volume of pressure vessel is $17.36 \mathrm{~m}^{3}$. When is filled with water, the gravity of water on pressure vessel should be equal with the adding of reaction of supports.

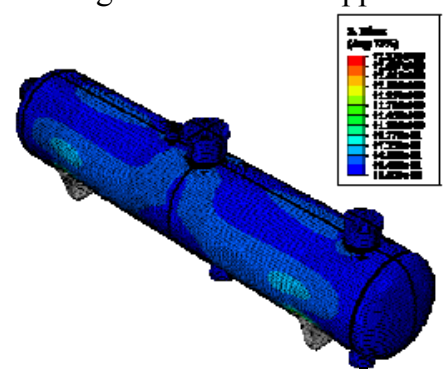

(a) Mises stress distribution

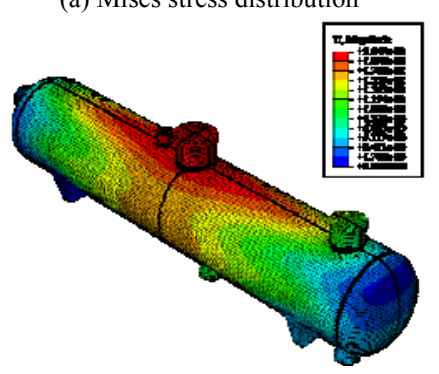

(b) Displacement distribution
Figure 6. Finite element calculation results of pressure vessel under hydraulic loading

Comparing extraction bearing reaction of supports with theoretical calculation of gravity water comparison:

1) Filled with water gravity

$\mathrm{G}=\mathrm{mg}=\rho v g=1000 \mathrm{~kg} / \mathrm{m}^{3 *} 17.36 \mathrm{~m}^{3} * 9.8 \mathrm{~N} / \mathrm{kg}=70128 \mathrm{~N}$

2) Using ABAQUS calculated a reaction of supports

Left bearing of pressure vessel: $F 1=85210.6 \mathrm{~N}$

Right bearing of pressure vessel: $\quad F 2=85245.7 \mathrm{~N}$

The sum of left and right bearing reaction of supports: $\mathrm{F}=\mathrm{F} 1+\mathrm{F} 2=170456.3 \mathrm{~N}$

3) Error:

$(\mathrm{F}-\mathrm{G}) / \mathrm{G} * 100 \%=(170456.3-170128) / 170128=0.2 \%$

Error within the scope of the permit, so using ABAQUS calculation results is effective.

\section{CALCULATION OF PRESSURE VESSEL UNDER UNIFORM INTERNAL PRESSURE OF THE MECHANICAL RESPONSE}

Load is the design internal pressure $\mathrm{P}=14 \mathrm{MPa}$ of pressure vessel and internal pressure is distributed in the inner wall of pressure container. Fig. 7 is the loading plan of uniform internal pressure.

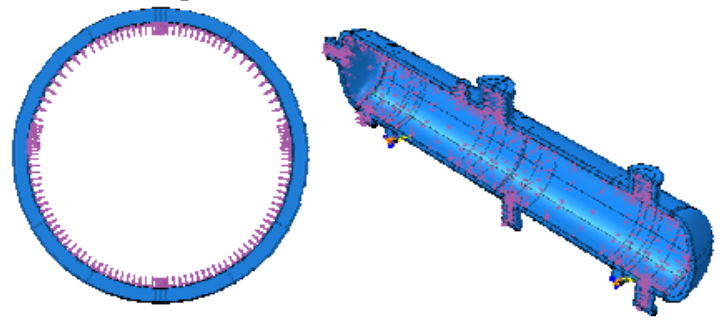

Figure 7. Schematic diagram of pressure vessel under uniform internal pressure load

The following is the calculation results of finite element. Fig.8(a) is Mises stress distribution of pressure vessel under internal pressure load. Fig.8(b) is displacement profile of pressure vessel under internal pressure load. Under the action of internal pressure, stress distribution on pressure vessel is in an average of about $150 \mathrm{mpa}$, and stress reached $400 \mathrm{mpa}$ on the inner wall of pressure vessel' nozzle which surpasses the yield strength of material. In this paper, the part2 will explain that this phenomenon is allowed, and will use sub model technique to further calculate the local mechanical response of nozzle. 


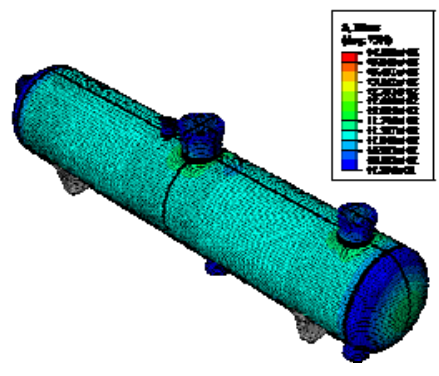

(a) Mises stress distribution

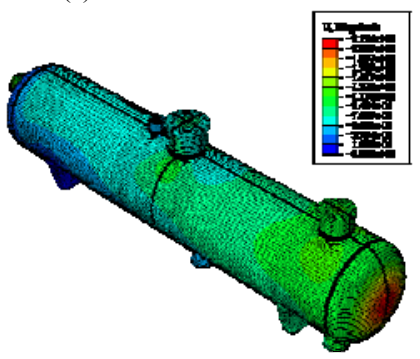

(b) Displacement distribution

Figure 8. Calculation results of pressure vessel under internal pressure

\section{CONCLUSIONS}

Through the simulation analysis method of finite element, first of all, this research, successfully set up an overall geometric model of a complex pressure vessel and the model is partitioned by structured grid. Secondly, the finite element calculation was carried on for three load situation separately of pressure vessel under dead weight, hydraulic, internal pressure, getting stress/strain response in various cases of pressure vessel, comparing the finite element calculation with the theoretical calculation value to verify the correctness of the simulation model and the effectiveness of the grid. Finally, a series of calculation results provides important data used for contrasting and verifying for the mechanical response study of pressure vessel under complex loads.

In the numerical calculation process, the part of maximum stress of pressure vessel appears in the uppermiddle part of the nozzle wall, which has been proved in the experiment. At the same time, it shows that subsequent research emphasis of sub model should also be put around the nozzle.

\section{ACKNOWLEDGMENT}

Supported by Research and Development Funded Projects of Lanzhou University of Technology (01-0278) and the Natural Science Foundation of Gansu Province, China(2011GS04332).

\section{REFERENCES}

1] Zhang Guang-xiang. Actuality and advance on failure analysis and safety assessment technology of pressure vessels[J]. China Public Security·Academy Edition,2008,13(2): 152-156.

[2] Zhong Qun-peng, Li Xue-ren. Chinese pressure vessel safety evaluation technology application and development[J]. China boiler pressure vessel safety,1997,13(2): 4-8.

[3] Wang Ning-feng. Review on the development of fatigue design methods[J]. Journal of Qinghai University,2004,22(5): 20-24.

[4] Wang Wen-he, Yu Xiao-chun, Shen Shi-ming. Situation and development of the safety assessment methods for the pressure piping with defects[J]. Pipeline Technique and Equipment,2007,(2): $1-3$.

[5] Shi Yi-rong, Zhou Yu-rong. ABAQUS finite element analysis example explanation[M]. China Machine Press, 2006.

[6] Zhang Jing-qiang. Under the action of impact load of pressure vessel, mechanical response test research[J]. Science and technology information (academic research), 2007,(20):9-11.

[7] Huang Xiao-guang, Han Zhong-ying. Contact Analysis of Pressure Vessel Based on ABAQUS[J]. Petro-chemical Equipment, 2011,40(2):35-39. 